\title{
The Role of Cardiac Magnetic Resonance Imaging in the Determination of Cardiovascular Anomalies in Children and Young Adults with Turner Syndrome
}

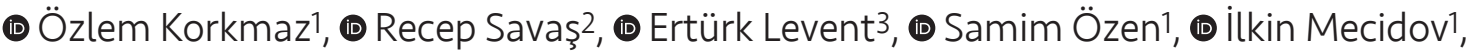 \\ (1) Damla Gökşen1, (1) Şükran Darcan¹ \\ 1Ege University Faculty of Medicine, Department of Pediatric Endocrinology and Diabetes, Izmir, Turkey \\ 2Ege University Faculty of Medicine, Department of Radiology, İzmir, Turkey \\ ${ }^{3}$ Ege University Faculty of Medicine, Department of Pediatric Cardiology, İzmir, Turkey
}

\begin{abstract}
Aim: Congenital cardiovascular (CV) anomalies and aortic dilatation are common in patients with Turner syndrome. The aim of this study was to compare echocardiography (ECHO) findings with CV anomalies and aortic dilatation identified using magnetic resonance imaging (MRI) in children and young adults with Turner syndrome.
\end{abstract}

Materials and Methods: Twenty-six girls with Turner syndrome aged 11-20 years were recruited through tertiary centers. CV anomalies and aortic diameter were evaluated using CV-MRI. Auxological measurements, karyotype analyses, medical therapies (growth hormone, estrogen, and thyroid replacement therapy) and transthoracic ECHO findings were recorded for all participants.

Results: Normal cardiac anatomy was identified in 16 (61.5\%) of our 26 cases, with no cardiac pathology being identified via either CV-MRI or ECHO. CV anomalies were identified in 5 of the 26 (19.2\%) patients via CV-MRI. Aortic dilatation was determined in four patients (one with descending and ascending aorta, one with ascending aorta, and two with descending aorta). Aortic size index was $<2 \mathrm{~cm} / \mathrm{m}^{2} \mathrm{in}$ all patients. $\mathrm{ECHO}$ was normal for the three patients with malformations detected via CV-MRI.

Conclusion: CV-MRI identifies significant cardiac lesions missed by ECHO in pediatric patients with Turner syndrome, especially aortic dilatation and other vascular anomalies.

Keywords: Turner syndrome, cardiac magnetic resonance imaging, cardiovascular anomalies

\section{Introduction}

Turner syndrome, or monosomy $\mathrm{X}$, is caused by a complete or partial absence of one of the two normal X-chromosomes (1). It affects one in 2000 live-born females. The most serious clinical aspect of the syndrome is due to congenital and/or acquired cardiovascular diseases (CVD). CV morbidity has been estimated to affect approximately
$50 \%$ of patients with Turner syndrome. CV anomalies include bicuspid aortic valve (BAV), persistent left superior vena cava, anomalous pulmonary venous return, elongation of the transverse aorta, coarctation of the aorta, aortic dissection, and dilatation and pseudocoarctation of the aorta (2-4). However, the syndrome has also been associated with other arterial and venous anomalies. The incidence of 
CV lesions ranges from $23 \%$ to $45 \%(3,5)$. Mortality rates are three times higher in women with Turner syndrome than in the normal female population (1). Shortened lifespan is often due to CV complications, such as aortic dilatation and dissection (6). Transthoracic echocardiography (ECHO) and $\mathrm{CV}$-magnetic resonance imaging (MRI) are the principal methods used for the diagnosis and surveillance of these conditions (7). A high prevalence of structural anomalies in patients with Turner syndrome that are not revealed via $\mathrm{ECHO}$ have been detected using CV-MRI. Although ECHO is a standard method for evaluating cardiac anatomy in Turner syndrome patients, its usefulness in the evaluation of vascular anomalies is limited. CV-MRI is recommended for the management of patients with Turner syndrome (7-9). The aim of this study was to compare ECHO findings with $\mathrm{CV}$ anomalies and aortic dilatation identified using MRI in children and young adults with Turner syndrome.

\section{Materials and Methods}

Twenty-six girls and women with Turner syndrome aged 11-20 years were enrolled in this study. Subjects able to tolerate CV-MRI without sedation were included, and patients less than 11 years were therefore excluded. Relevant clinical data, including auxological measurements (weight, weight standard deviation score (SDS), height, height SDS, body mass index (BMI), and BMI-SDS), karyotype analyses, and medical therapies (growth hormone, estrogen, and thyroid replacement therapy) were recorded. Body surface area (BSA) was calculated based on the formula described by Du Bois and Du Bois (10). ECHO findings were recorded retrospectively.

The authors assert that all procedures contributing to this work comply with the ethical standards of the relevant national guidelines on human experimentation (Ege University) and with the Helsinki Declaration of 1975, as revised in 2008, and have been approved by the institutional committees of Ege University (approval number: 18-7.1/31). Informed consent was obtained.

\section{Magnetic Resonance Imaging}

All patients underwent imaging on a 3 Tesla MR scanner (Verio, Siemens Medical Systems) using a body coil and included axial T2 weighted (W) HASTE sequences. MR angiography was conducted with flash 3D coronal images and $0.2 \mathrm{mmol} / \mathrm{kg}$ of Gadolinium-chelate contrast media administered through an antecubital vein with a MR compatible injector (Ulrich, Germany). Post gadolinium axial T1-W-VIBE images also were performed. The diameters of the ascending and descending aorta were measured on axial T1-W images at the level of the right pulmonary artery, perpendicular to the long axis of the ascending aorta in a blinded fashion.

All participants tolerated CV-MRI without sedation or complications. Measurements were recorded for ascending and descending aortic diameter and pulmonary conus diameter, and aortic size index (ASI) (ascending aorta/BSA). Measurements were standardized by BSA to determine $z$-scores. The aorta and pulmonary conus were considered dilated in cases of a z-score greater than 2. ASI values were also calculated $\left(\mathrm{cm} / \mathrm{m}^{2}\right)$. Aortic coarctation, transverse arch, bovine arch, left vertebral artery anomaly, aberrant right subclavian artery, persistent left superior vena cava and partial pulmonary venous return anomaly were recorded.

\section{Statistical Analyses}

Descriptive statistics were used for data analysis. Continuous data were expressed as mean values with ranges. z-scores were calculated for weight, height, and $\mathrm{BMI}$, and represented as mean values [ \pm standard deviation (SD)]. The frequencies of vascular anomalies and cardiac lesions were analyzed, and any disparity between $\mathrm{ECHO}$ and CV-MRI findings was noted.

\section{Results}

Twenty-six girls with Turner syndrome, aged 11-20 years of age, were included in the study. Mean age at investigation was $16.6 \pm 2.8$ years. The patients' clinical characteristics are shown in Table I. Karyotype analysis revealed $57.7 \% \quad(n=15)$ 45,X monosomy, 30.8\% ( $n=8)$ mosaicism, and $11.5 \%(n=3)$ isochromosome. In terms of treatment, $84.4 \%(n=23)$ of the patients received growth hormone therapy. CV anomalies were identified in five of the 26 (19.2\%) patients via CV-MRI. Of these, $45, X$ monosomy karyotypes were identified in four and $46, X, i(X q)$ in one. CV-MRI revealed pseudocoarctation in two patients, aberrant right subclavian artery in two, and azygos lobe fissure variations in one. An appearance compatible with bicuspid aorta was identified via $\mathrm{ECHO}$ in one case in which pseudocoarctation was detected via CV-MRI and in one patient with right aberrant subclavian artery detected via CV-MRI. ECHO was normal for the other three patients with a malformation detected via CV-MRI. CV-MRI was normal in two cases in which ASD secundum was detected via ECHO (Table II).

Mean \pm SD of ascending aortic diameter $2.16 \pm 0.29 \mathrm{~cm}$ and z-score $0.08 \pm 1.4$, descending aortic diameter $1.63 \pm 0.30$ $\mathrm{cm}$ and $\mathrm{z}$-score $-0.07 \pm 1.34$, and pulmonary conus diameter 
$1.91 \pm 0.47 \mathrm{~cm}$ and $z$-score $-0.94 \pm 1.59$ were detected. The mean \pm SDASI was $1.44 \pm 0.24 \mathrm{~cm} / \mathrm{m}^{2}$ (Table III). Aortic dilatation was determined in four patients $(15.3 \%)$ in our study (one with descending and ascending aorta, one with ascending aorta, and two with descending aorta). ASI was $<2 \mathrm{~cm} / \mathrm{m}^{2}$ in all patients.

\section{Discussion}

CV-MRI is the gold standard method for the diagnosis and follow-up of thoracic aorta morphological anomalies in patients with Turner syndrome (7). Transthoracic ECHO may be of limited use in assessing the anatomy in an abnormally shaped chest, and can underestimate the size of both the ascending and descending aorta in patients with Turner syndrome. Although CV-MRI is clearly recommended in the

Table I. Clinical characteristics of study participants with Turner syndrome

\begin{tabular}{|l|l|}
\hline Age at investigation (year) & $16.6 \pm 2.8$ \\
\hline Weight SDS & $-0.06 \pm 1.33^{*}$ \\
\hline Height SDS & $-1.96 \pm 1.14^{*}$ \\
\hline BMI-SDS & $1.24 \pm 0.99^{*}$ \\
\hline BSA $\left(\mathrm{m}^{2}\right)$ & $1.48(1.30-1.58)^{*}$ \\
\hline $45, X$ monosomy & $15 / 26(57.7 \%)^{* *}$ \\
\hline Mosaicism & $8 / 26(30.8 \%)$ \\
\hline Isochromosome & $3 / 26(11.5 \%)$ \\
\hline Growth hormone therapy & $23 / 26(88.4 \%)^{* *}$ \\
\hline Estrogen-replacement therapy & $22 / 26(84.6 \%)^{* *}$ \\
\hline Thyroid-replacement therapy & $4 / 26(15.3 \%)^{* *}$ \\
\hline
\end{tabular}

*Variables are represented as means \pm standard deviation, ${ }^{* *}$ Categorical variables are represented as frequencies (\%)

SDS: Standard deviation score, BMI: Body mass index, BSA: Body surface area

Table II. Comparison of CV-MRI findings with echocardiography

\begin{tabular}{|l|l|l|l|}
\hline \multicolumn{2}{|l|}{ CV-MRI } & \multicolumn{2}{|l|}{ Echocardiography } \\
\hline Findings & $\mathbf{n}$ & Findings & $\mathbf{n}$ \\
\hline \multirow{2}{*}{ Aberran right subclavian artery } & \multirow{2}{*}{2} & Bicuspid aorta & 1 \\
\cline { 3 - 4 } & & Normal & 1 \\
\hline \multirow{2}{*}{ Pseudocoarctation } & \multirow{2}{*}{2} & Bicuspid aorta & 1 \\
\cline { 3 - 4 } & & Normal & 1 \\
\hline Azygos lobe fissure variation & 1 & Normal & 1 \\
\hline \multirow{2}{*}{ Aortic dilatation } & \multirow{2}{*}{4} & Bicuspid aorta & 1 \\
\cline { 3 - 4 } & & Normal & 3 \\
\hline Normal & 17 & Secundum ASD & 2 \\
\hline
\end{tabular}

CV-MRI: Cardiovascular-magnetic resonance imaging, ASD: Atrial septal defect guidelines, the optimal timing of the first imaging is not well established. CV-MRI is used in older girls and adults who are able to tolerate the procedure without sedation. Subsequent routine imaging is recommended every 5-10 years (11). Patients over 10 years of age and evaluated with MRI without the need for sedation were included in our study group.

Growth hormone deficiency is associated with increased CV risk (12). Growth hormone and the 45, $X$ monosomy karyotype correlate with a dilated proximal aorta (13). Donadille et al. (14) emphasized that patients with monosomy $\mathrm{X}$ in a cohort study should be monitored more closely in CV terms. Karyotype analysis revealed $45, X$ monosomy in four of the five patients with cardiac anomaly detected via CV-MRI and in all four patients with enlarged aortic diameter. Except for one patient in whom an aberrant right subclavian artery anomaly was detected, all cases were treated with growth hormone.

Pseudocoarctation of the aortic arch is a rare congenital anomaly which resembles true coarctation and is caused by the presence of a narrowing in the descending thoracic aorta immediately distal to the origin of the left subclavian artery (15). In our study, pseudocoarctation was detected in two cases via cardiac MRI, but this finding was not detected using $\mathrm{ECHO}$ in one case.

Ho et al. (2) estimated a prevalence of aberrant right subclavian artery frequency in Turner syndrome of $8 \%$, compared to $0.4-2 \%$ in the normal population (16). In our study, an aberrant right subclavian artery anomaly was detected with CV-MRI in two cases. BAV is also common in Turner syndrome (17). In their comparison of CV-MRI and ECHO, Ostberg et al. (8) demonstrated an 18\% prevalence of BAV based on ECHO findings (CV-MRI data were not shown). BAV has been determined in $1.5-17.5 \%$ of children and adults with Turner syndrome using CV-MRI and ECHO $(3,4)$. Bicuspid aorta was determined in three patients via $\mathrm{ECHO}$ in our study. None of these patients exhibited valve pathology via CV-MRI.

Table III. CV-MRI measurement data of study group

\begin{tabular}{|l|l|l|}
\hline & $\begin{array}{l}\text { Mean } \pm \\
\text { standard } \\
\text { deviation }\end{array}$ & z-score \\
\hline Ascending aortic diameter $(\mathrm{cm})$ & $2.16 \pm 0.29$ & $0.08 \pm 1.4$ \\
\hline Descending aortic diameter $(\mathrm{cm})$ & $1.63 \pm 0.30$ & $-0.07 \pm 1.34$ \\
\hline Pulmonary conus diameter $(\mathrm{cm})$ & $1.91 \pm 0.47$ & $-0.94 \pm 1.59$ \\
\hline Aortic size index $\left(\mathrm{cm} / \mathrm{m}^{2}\right)$ & $1.44 \pm 0.24$ & - \\
\hline
\end{tabular}

CV-MRI: Cardiovascular-magnetic resonance imaging 
A greater incidence of interrupted inferior vena cava with azygos continuation has also been reported in patients with Turner syndrome $(3,4)$. A variation of azygos lobe fissure was detected in one patient via MRI in our study.

It is generally agreed that patients with Turner syndrome have a significantly elevated risk of aortic dissection. The few risk factors described include hypertension, the presence of BAV or coarctation, and dilatation of the aorta $(8,18)$. Dilatation of the aorta in certain anatomical locations has been associated with an increased risk of dissection. Castro et al. (19) CV-MRI study of children and young adults with Turner syndrome reported aortic dilatation in $26.7 \%$ of patients. Another pediatric study reported an incidence of aortic dilatation of $37 \%$ in Turner syndrome patients (13). In a study of children and young adults with Turner syndrome by Yiğit et al. (20), CV-MRI and 3D contrastenhanced MRI angiography revealed incidences of BAV of $19.6 \%$, coarctation of $6.5 \%$, ascending aorta dilatation of $28.3 \%$ and descending aorta dilatation of $15.2 \%$. BAV was identified as an important risk factor for aortic dilatation. In another study, possession of the $45, \mathrm{X}$ karyotype and BAV predicted dilatation of the ascending aorta, but dilatation of the descending aorta was only observed in patients with coarctation (21). In our study, one patient with a dilated aortic diameter had a bicuspid aortic appearance via ECHO. Karyotype analysis was 45,X monosomy in all cases in which we detected aortic dilatation. ASI is a method used to evaluate the degree of aortic disease. A ratio of $2 \mathrm{~cm} / \mathrm{m}^{2}$ requires close follow-up, while values $>2.5 \mathrm{~cm} / \mathrm{m}^{2}$ require transfer to an experienced center. ASI >2 $\mathrm{cm} / \mathrm{m}^{2}$ is considered to represent an absolute contraindication for pregnancy $(22,23)$. ASI values were $<2 \mathrm{~cm} / \mathrm{m}^{2}$ in all our patients.

\section{Study Limitations}

One of the limitations of our study was the small sample size. Further research with a larger patient series, especially in the pediatric age group, is now needed. The second limitation is that breathing and cardiac artefacts may have prevented the correct viewing of the CV-MRI.

\section{Conclusion}

CV-MRI should be performed on patients with Turner syndrome even if ECHO reveals a normal cardiac anatomy. CV-MRI can identify significant cardiac lesions missed by $\mathrm{ECHO}$ in pediatric patients with Turner syndrome, especially aortic dilatation and other vascular anomalies. Early diagnosis and an early institution of preventative and medical measures are critical for preserving the quality of life and increasing the lifespan in Turner syndrome patients.

\section{Ethics}

Ethics Committee Approval: The authors assert that all procedures contributing to this work comply with the ethical standards of the relevant national guidelines on human experimentation (Ege University) and with the Helsinki Declaration of 1975, as revised in 2008, and have been approved by the institutional committees of Ege University (approval number: 18-7.1/31).

Informed Consent: Informed consent was obtained.

Peer-review: Externally peer-reviewed.

\section{Authorship Contributions}

Surgical and Medical Practices: Ş.D., D.G., R.S., E.L., Concept: S.Ö., Ö.K., Design: S.Ö., Ö.K., Ş.D., Data Collecting or Processing: Ö.K., I.M., Analysis or Interpretation: R.S., S.Ö., Ö.K., Literature Search: Ö.K., Writing: Ö.K., R.S.

Conflict of Interest: No conflict of interest was declared by the authors.

Financial Disclosure: The authors declared that this study received no financial support.

\section{References}

1. Schoemaker MJ, Swerdlow AJ, Higgins CD, et al. Mortality in women with Turner syndrome in Great Britain: A national cohort study. J Clin Endocrinol Metab 2008;93:4735-42.

2. Ho VB, Bakalov VK, Cooley M, et al. Major vascular anomalies in Turner syndrome: Prevalence and magnetic resonance angiographic features. Circulation 2004;110:1694-700.

3. Dawson-Falk KL, Wright AM, Bakker B, Pitlick PT, Wilson DM, Rosenfeld RG. Cardiovascular evaluation in Turner syndrome: Utility of MR imag-ing. Australas Radiol 1992;36:204-9.

4. Kim HK, Gottliebson W, Hor K, et al. Cardiovascular anomalies in Turner syndrome: Spectrum, prevalence, and cardiac MRI findings in a pediatric and young adult population. AJR Am J Roentgenol 2011;196:454-60.

5. Mazzanti L, Cacciari E. Congenital heart disease in patients with Turner's syndrome: Italian Study Group for Turner Syndrome (ISCTS). J Pediatr 1998;133:688-92.

6. Gravholt $\mathrm{CH}$, Landin-Wilhelmsen K, Stochholm K, et al. Clinical and epidemiological description of aortic dissection in Turner's syndrome. Cardiol Young 2006;16:430-6.

7. Mortensen KH, Gopalan D, Norgaard BL, Andersen NH, Gravholt $\mathrm{CH}$. Multimodality cardiac imaging in Turner syndrome. Cardiol Young 2016;26:831-41.

8. Ostberg JE, Brookes JA, McCarthy C, Halcox I, Conway GS. A comparison of echocardiography and magnetic resonance imaging in cardiovascular screening of adults with Turner syndrome. / Clin Endocrinol Metab 2004;89:5966-71.

9. Mortensen $\mathrm{KH}$, Hjerrild $\mathrm{BE}$, Stochholm K, et al. Dilation of the ascending aorta in Turner syndrome-a prospective 
cardiovascular magnetic resonance study. J Cardiovasc Magn Reson 2011;28:13-24.

10. Du Bois D, Du Bois E. A formula to estimate the approximate surface area if eight and weight be known. 1916. Nutrition 1989;5:303-11.

11. Bondy CA. Care of girls and women with Turner syndrome: A guideline of the Turner syndrome study group. I Clin Endocrinol Metab 2007;92:10-25.

12. Stochholm $\mathrm{K}$, Laursen $\mathrm{T}$, Green $\mathrm{A}$, et al. Morbidity and $\mathrm{GH}$ deficiency: A nationwide study. Eur / Endocrinol 2008;158:44757.

13. Somerville S, Rosolowsky E, Suntratonpipat S, Girgis R, Goot $\mathrm{BH}$, Tham EB. Cardiac magnetic resonance imaging in pediatric Turner syndrome. J Pediatr 2016;175:111-5.

14. Donadille B, Rousseau A, Zenaty D, et al. Cardiovascular findings and management in Turner syndrome: Insights from a French cohort Eur | Endocrinol 2012;167:517-22.

15. Klein LW, Levin IL, Weintraub WS, Agarwal JB, Helfant RH. Pseudocoarctation of the aortic arch in a patient with Turner's syndrome. Clin Cardiol 1984;7:621-3.

16. Freed $\mathrm{K}$, Low VH. The aberrant subclavian artery. AJR Am J Roentgenol 1997;168:481-4.
17. Gutmark-Little I, Backeljauw PF. Cardiac magnetic resonance imaging in Turner syndrome. Clin Endocrinol (Oxf) 2013;78:64658.

18. Matura LA, Ho VB, Rosing DR, Bondy CA. Aortic dilatation and dissection in Turner syndrome. Circulation 2007;116:1663-70.

19. Castro AV, Okoshi K, Ribeiro SM, et al. Cardiovascular assessment of patients with Ullrich-Turner's syndrome on Doppler echocardiography and magnetic resonance imaging. Arq Bras Cardiol 2002;78:51-8.

20. Yiğit H, Önder A, Özgür S, Aycan Z, Karademir S, Doğan V. Cardiac MRI and 3D contrast-enhanced MR angiography in pediatric and young adult patients with Turner syndrome. Turk I Med Sci 2017;47:127-33.

21. Mortensen $\mathrm{KH}$, Hjerrild BE, Andersen NH, et al. Abnormalities of the major intrathoracic arteries in Turner syndrome as revealed by magnetic resonance imaging. Cardiol Young 2010;20:191-200.

22. Matura LA, Ho VB, Rosing DR, Bondy CA. Aortic dilatation and dissection in Turner syndrome. Circulation 2007;116:1663-70.

23. Nijs J, Gelsomino S, Lucà F, Parise O, Maessen JG, Meir ML. Unreliability of aortic size index to predict risk of aortic dissection in a patient with Turner syndrome. World I Cardiol 2014;6:349-52. 